
\title{
25 Research Square \\ Effect of Hybrid Texture on Cutting Performance of WC/Co-based Coated Tools Turning Aluminum Alloy
}

\section{Yonghong Fu ( $\square$ fyh_ujs@163.com )}

School of Mechanical Engineering, Jiangsu University, Zhenjiang 212013, Jiangsu, China

Yun Zhou

School of Mechanical Engineering, Jiangsu University, Zhenjiang 212013, Jiangsu, China

\section{Zetan Yang}

School of Mechanical Engineering, Jiangsu University, Zhenjiang 212013, Jiangsu, China

Jie Yang

School of Mechanical Engineering, Jiangsu University, Zhenjiang 212013, Jiangsu, China

\section{Research Article}

Keywords: Hybrid texture, CrAlN coatings, Cutting performance, Adhesive wear

Posted Date: June 7th, 2021

DOI: https://doi.org/10.21203/rs.3.rs-570598/v1

License: (c) (1) This work is licensed under a Creative Commons Attribution 4.0 International License. Read Full License 


\section{Abstract}

When cutting aluminum alloy with WC/Co coated tools, severe adhesion and wear exist on the tool-chip contact interface, which are the major factors leading to failure of cutting tools. To address this problem and extend service life of cutting tools, this study introduced surface textures into coated tools, trying to integrate the anti-friction properties of micro-textures with the wear resistance properties of coatings to improve tribological characteristics of tools surface. Firstly, hybrid texture consisting of micro-scale pits and micro-scale grooves were fabricated on the rake surface close to the main cutting edge of carbide tools by picosecond laser. Subsequently, the textured tools were deposited with hard-coatings CrAIN via physical vapor deposition (PVD) technology and the hybrid textured CrAIN coated tool (MPG-T) was obtained eventually. Other texture combinations included micro-scale pits and micro-scale grooves distributed in the tool-chip contact zone. Wet cutting experiments were carried out on these prepared tools. Results showed that compared with micro-scale pitted coated tool (MP-T), micro-scale grooved (MG-T) and conventional coated tool (CCT), MPG-T tool performed better in cutting forces, friction coefficient, tool adhesion and wear on the rake face and the flank face, chip morphology. Moreover, the corresponding synergistic mechanisms of hybrid texture and coatings were proposed. It's suggested that applying the results to actual industries can enhance the cutting performance of coated tools in machining of aluminum alloy.

\section{Full-text}

Due to technical limitations, full-text HTML conversion of this manuscript could not be completed. However, the manuscript can be downloaded and accessed as a PDF.

\section{Tables}

Due to technical limitations, table 1-4 is only available as a download in the Supplemental Files section.

\section{Figures}



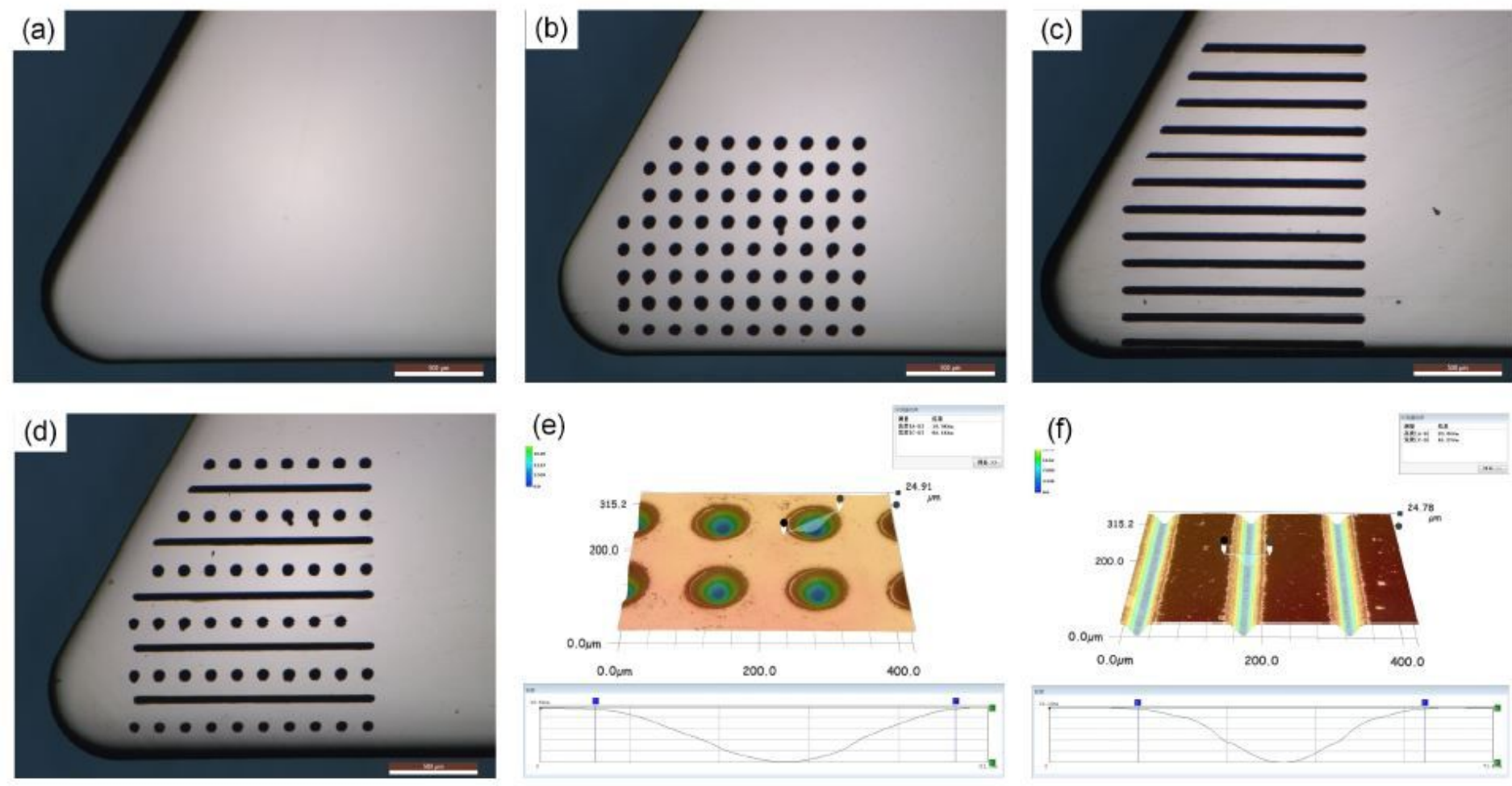

\section{Figure 1}

Micrographs of (a) untextured tool, (b) micro-scale pitted tool, (c) micro-scale grooved tool, (d) hybrid textured tool consisting of micro-pits and micro-grooves, $(e)$ and (f) three-dimension al morphology of two textures
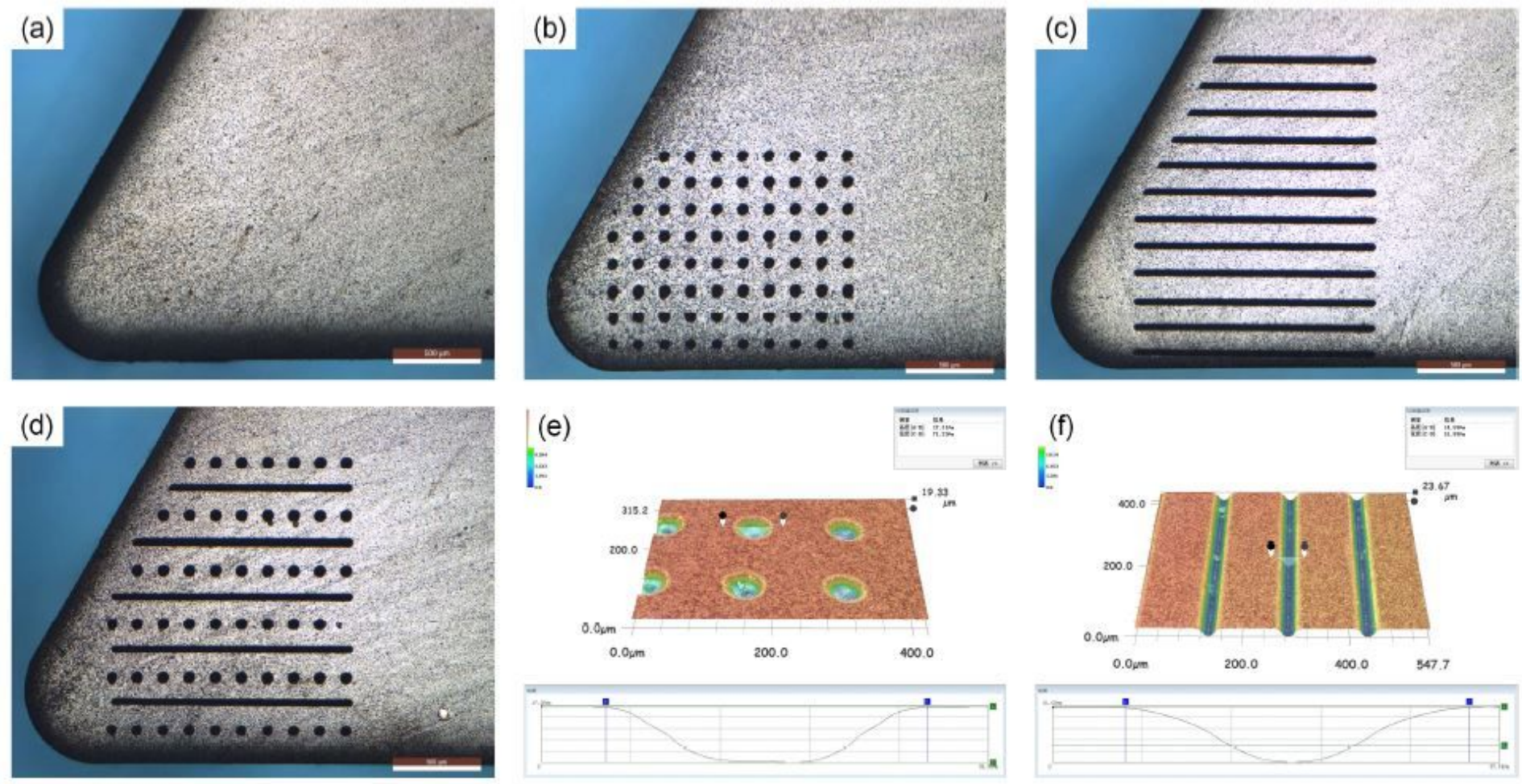
Figure 2

Micrographs of (a) untextured tool, (b) micro-scale pitted tool, (c) micro-scale grooved tool, (d) hybrid textured tool consisting of micro-pits and micro-grooves, (e) and (f) three-dimensional morphology of two textures deposited with CrAIN hard coatings

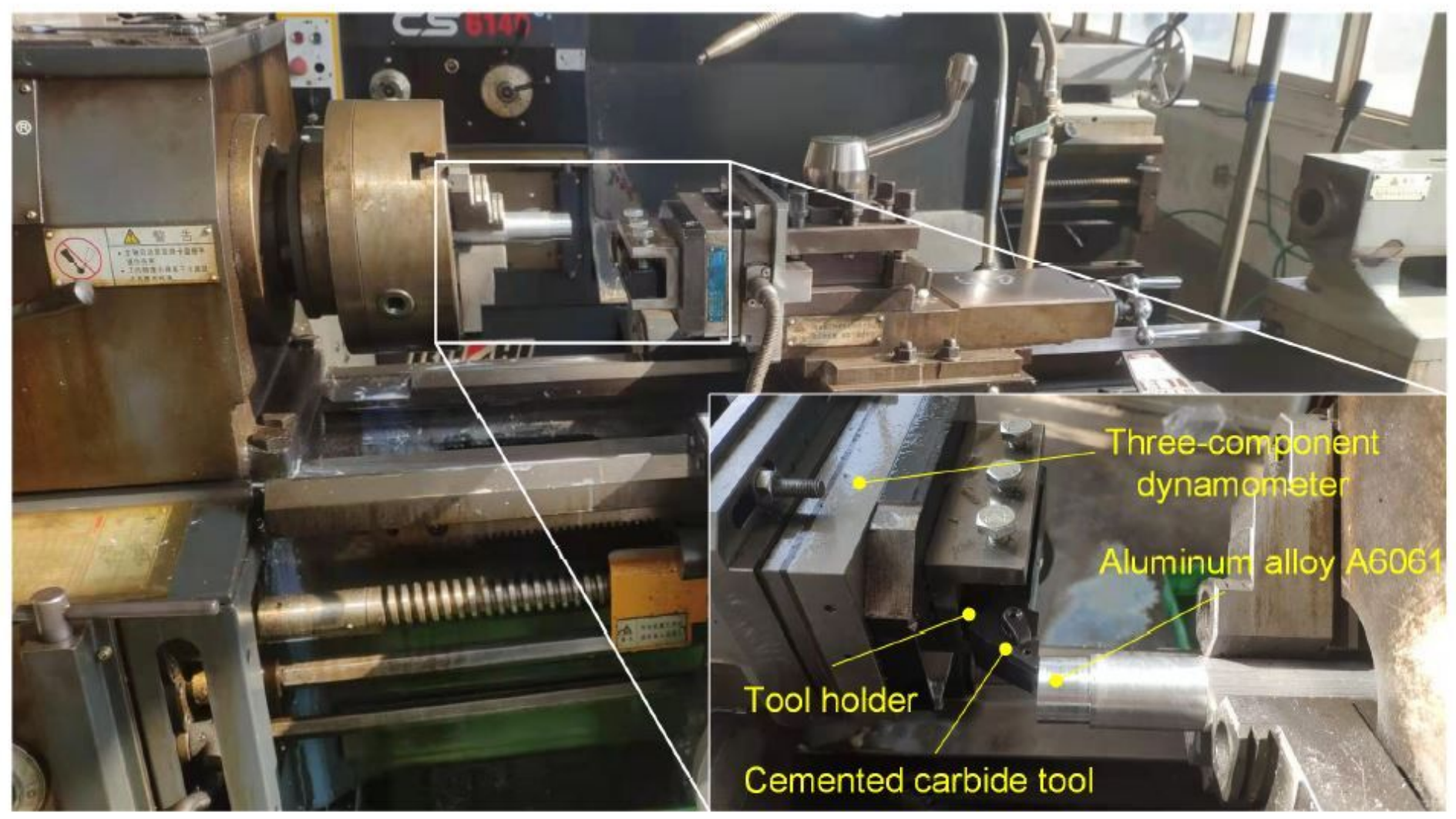

\section{Figure 3}

Orthogonal cutting experimental equipment 

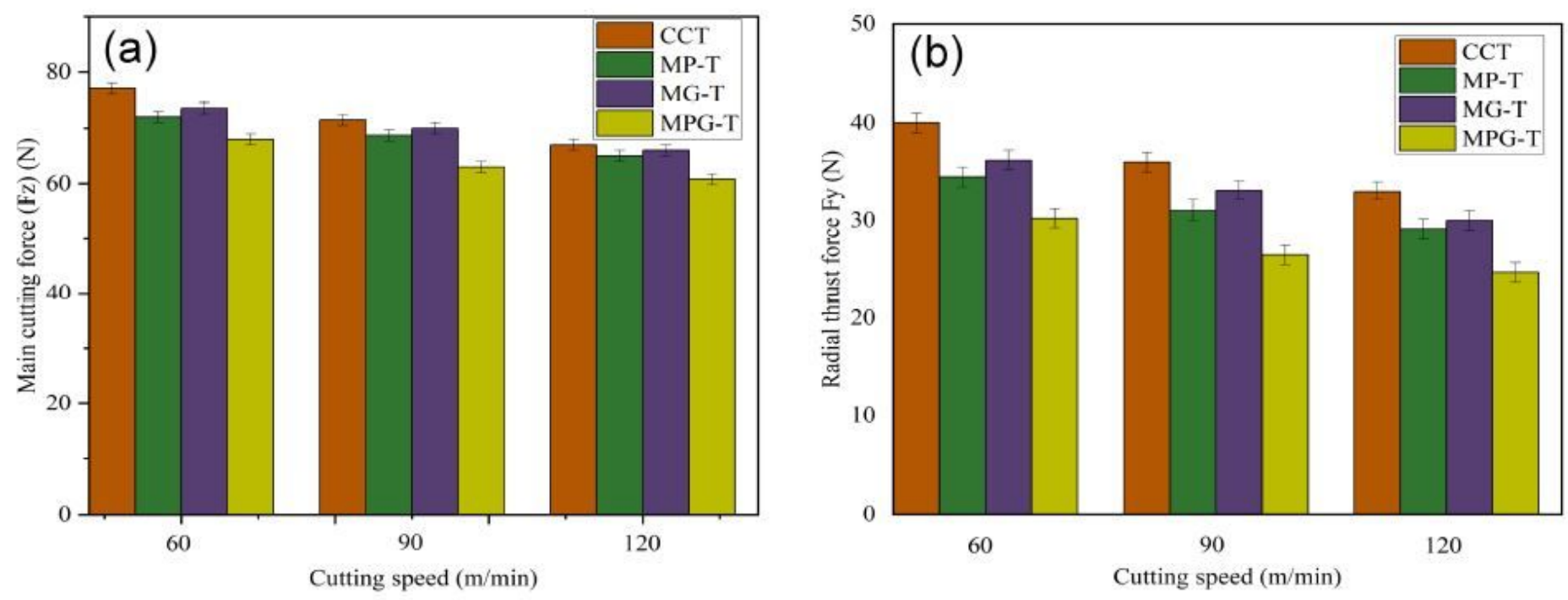

Figure 4

Cutting forces of CCT, MP-T, MG-T, MPG-T tools at three cutting speeds: (a) main cutting force Fz and (b) radial thrust force Fy

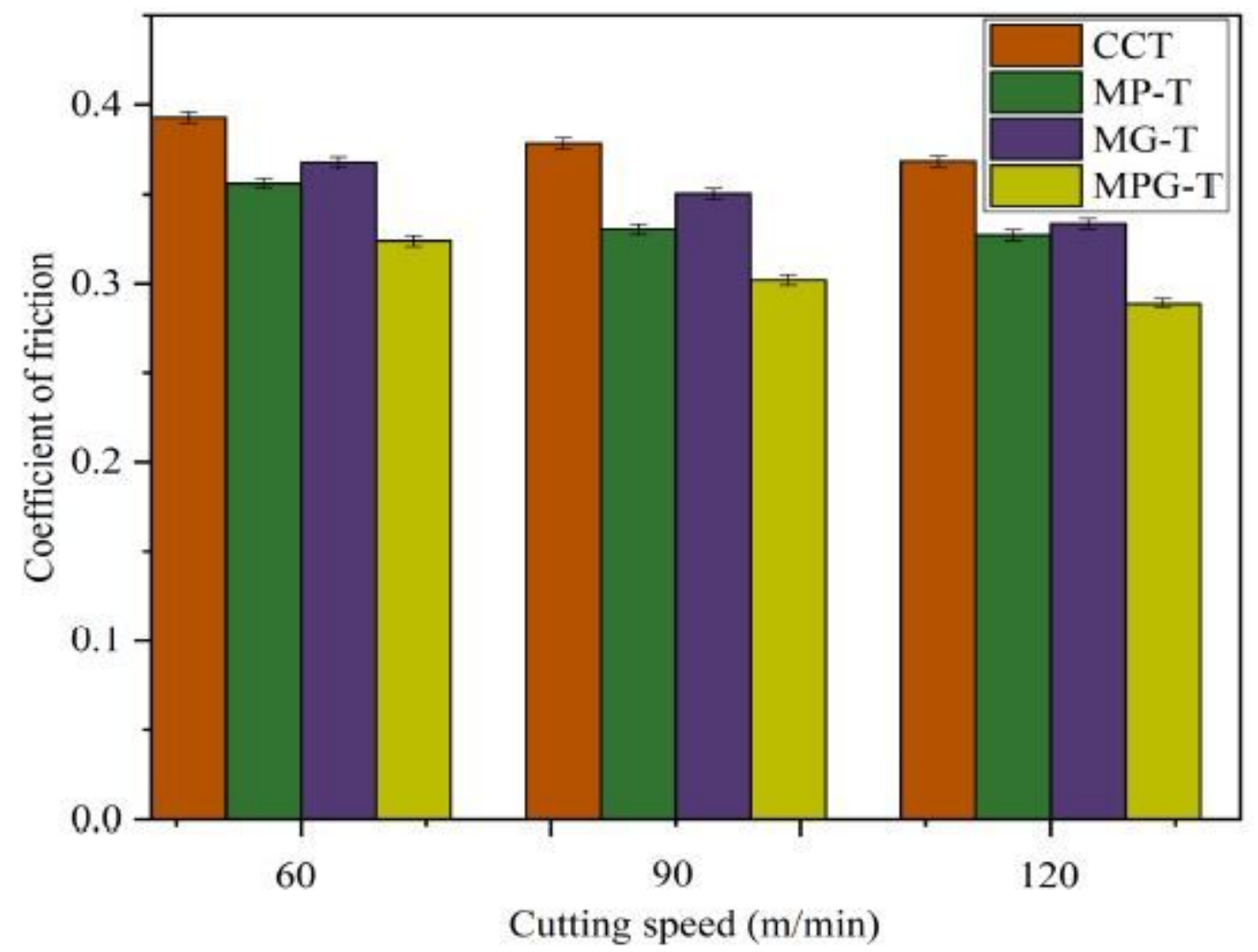


Figure 5

Coefficient of friction between the tool-chip interface of CCT, MP-T, MG-T and MPG-T tools at three cutting speeds

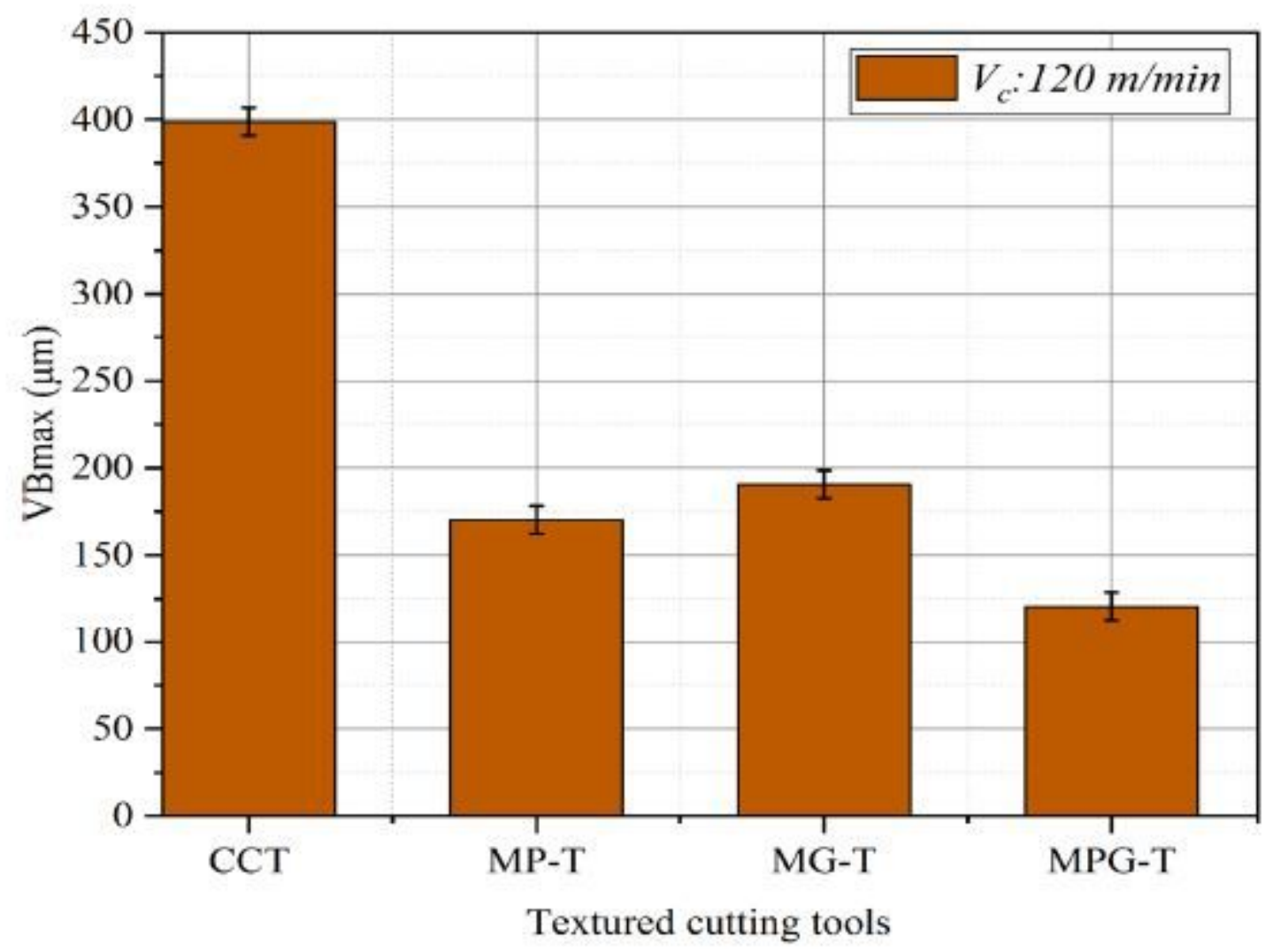

Figure 6

The maximum flank wear (VBmax) of CCT, MP-T, MG-T and MPG-T tools after 3 min of machining time at the speed of $120 \mathrm{~m} / \mathrm{min}$ 

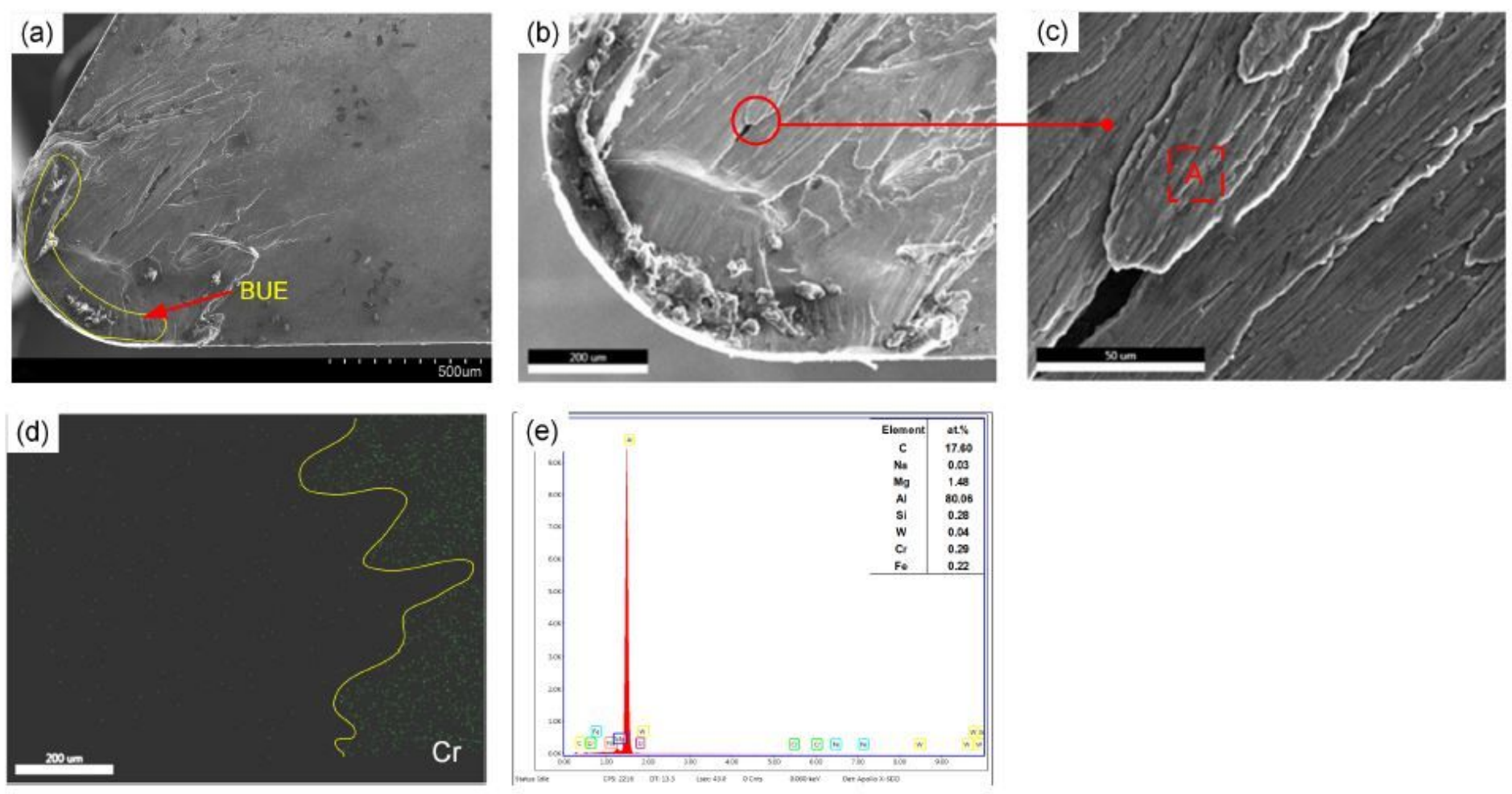

\section{Figure 7}

The wear micrograph (a-c) of CCT tool at the rake face and the SEM/EDS elemental analyses of point A (e), and the EDS maps of the distribution of Cr element on the tool wear surface (d) after 3 min wet cutting at the speed of $120 \mathrm{~m} / \mathrm{min}$ 

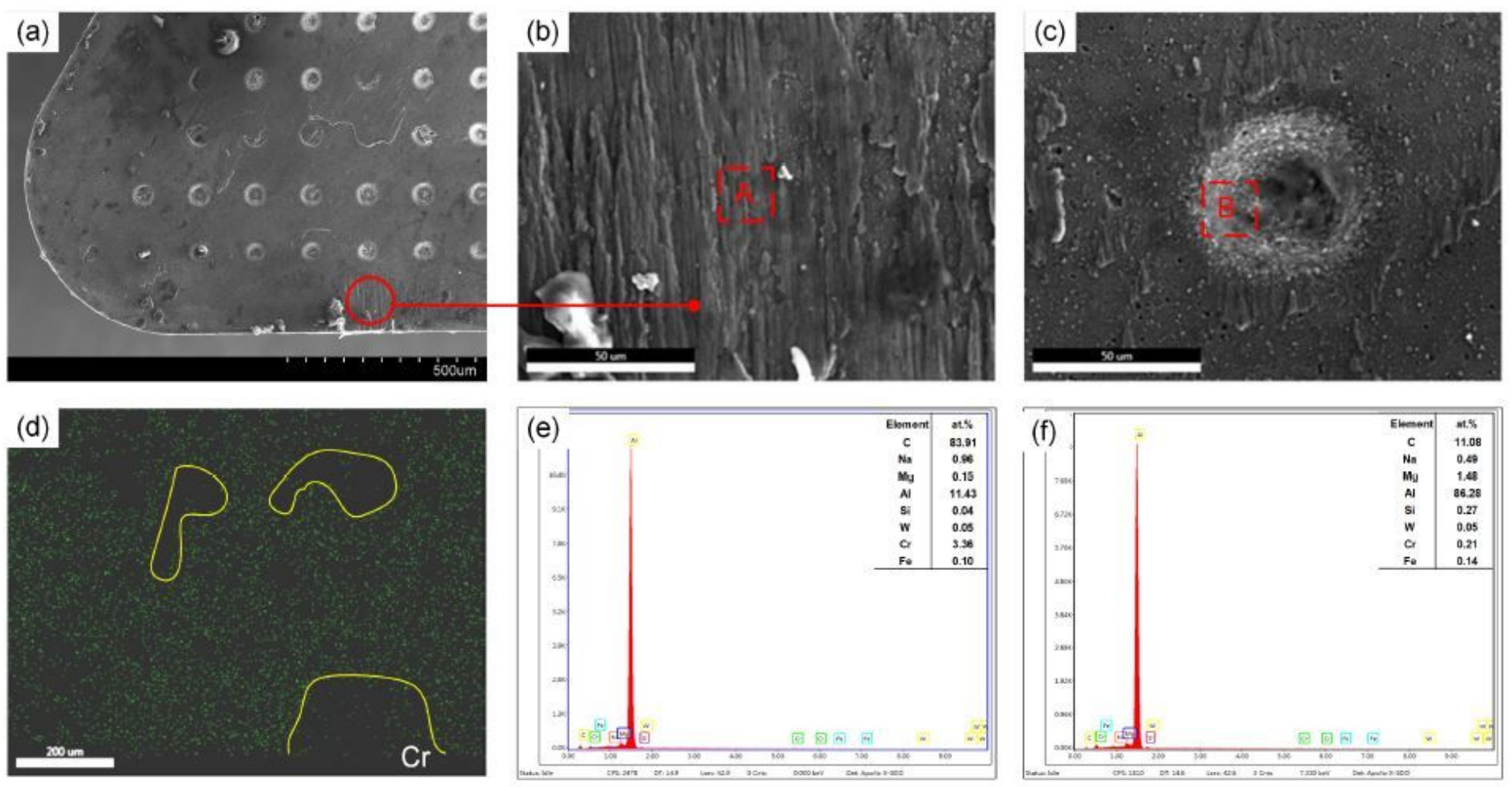

\section{Figure 8}

The wear micrograph (a-d) of MP-T tool at the rake face and the SEM/EDS elemental analyses of point A, $B(e, f)$, and the EDS maps of the distribution of Cr element on the wear surface (d) after 3 min wet cutting at the speed of $120 \mathrm{~m} / \mathrm{min}$ 

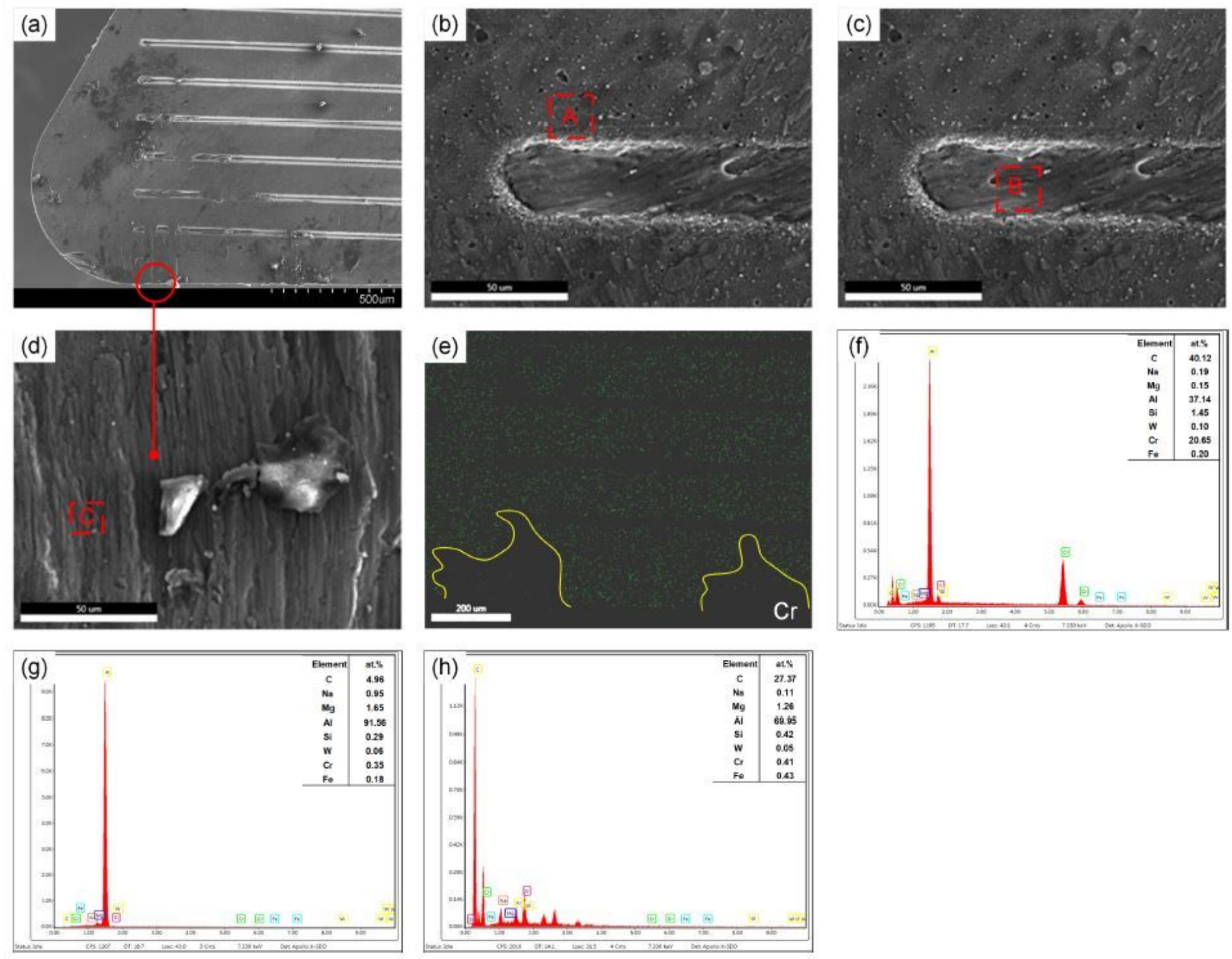

Figure 9

The wear micrograph (a-d) of MG-T tool at the rake face and the SEM/EDS elemental analyses of point A, $B$ and $C$ (f-h), and the EDS maps of the distribution of $\mathrm{Cr}$ element on the wear surface (e) after 3 min wet cutting at the speed of $120 \mathrm{~m} / \mathrm{min}$ 

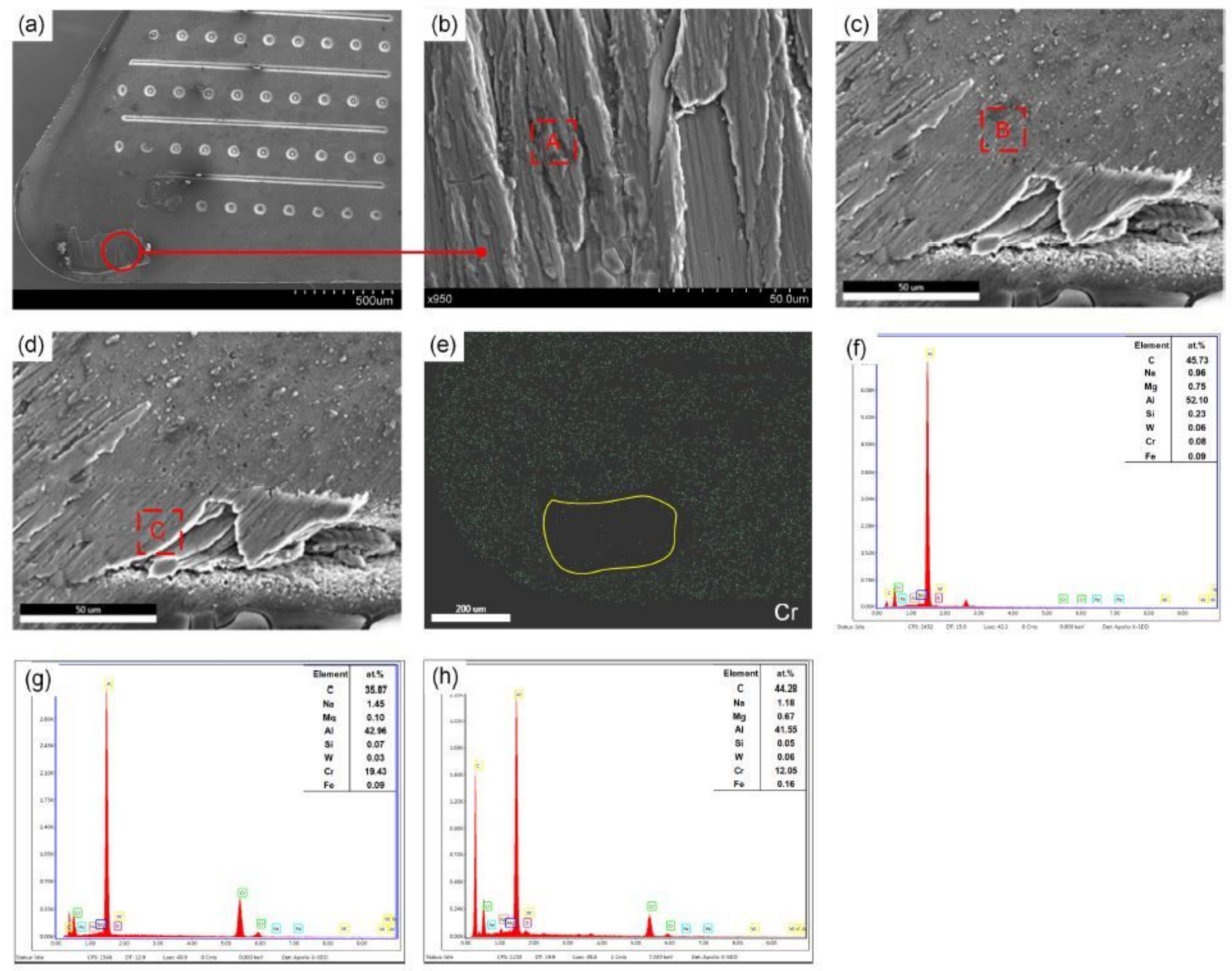

Figure 10

The wear micrograph (a-d) of MPG-T tool at the rake face and the SEM/EDS elemental analyses of point $A, B$ and $C(f-h)$, and the EDS maps of the distribution of Cr element on the wear surface (e) after 3 min wet cutting at the speed of $120 \mathrm{~m} / \mathrm{min}$ 

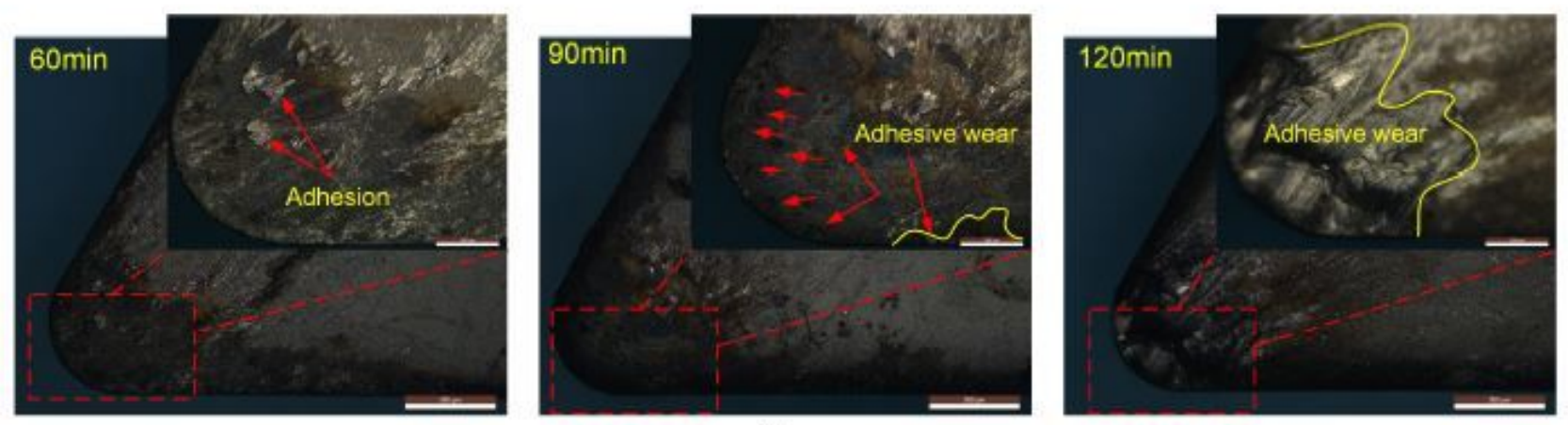

(a)
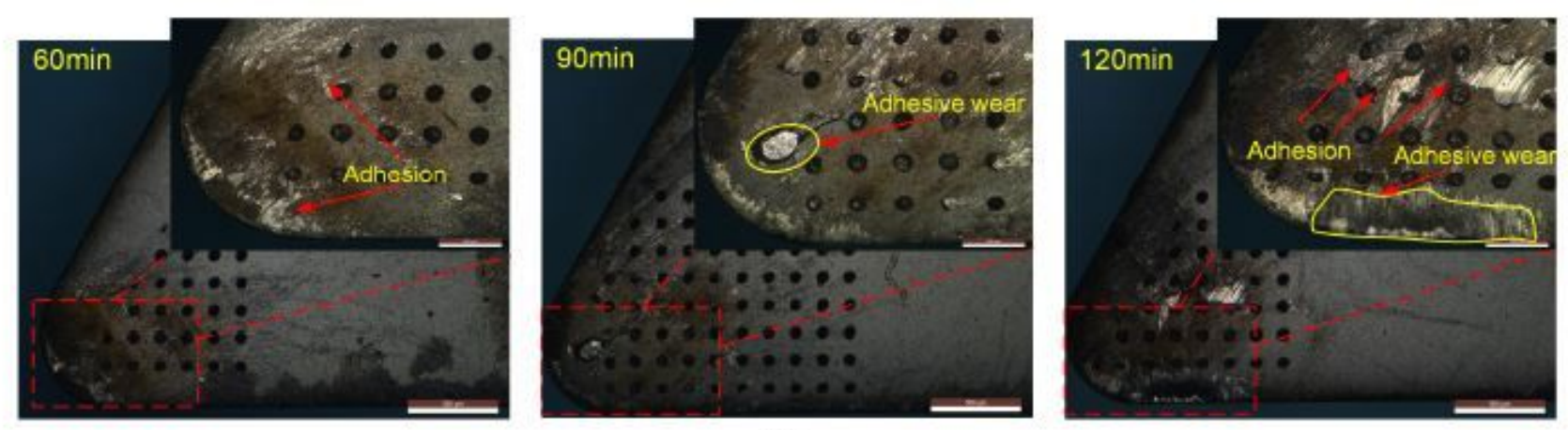

(b)
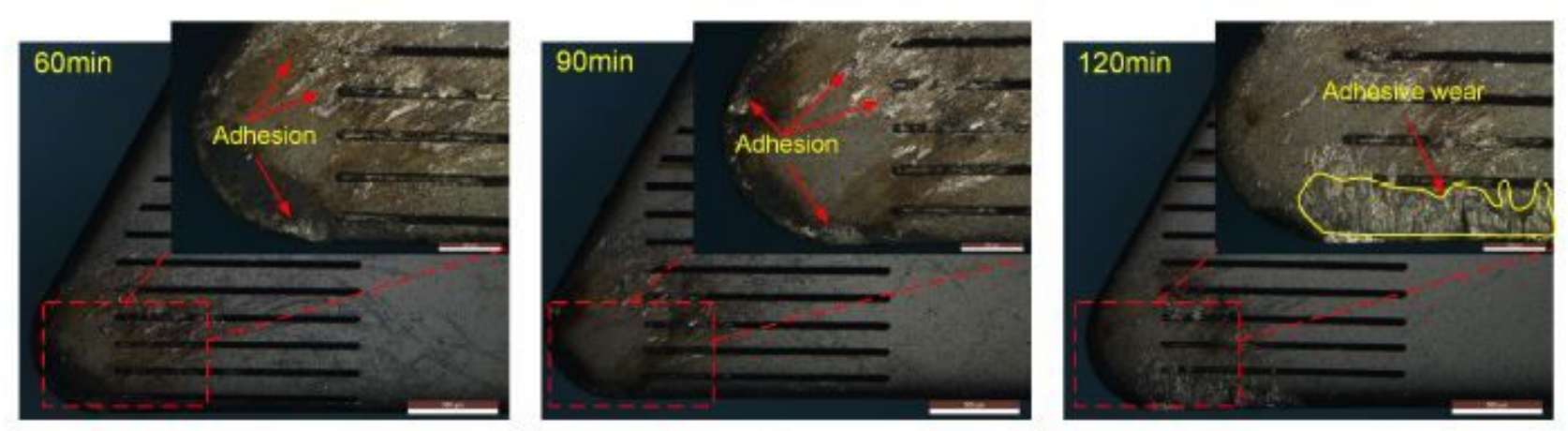

(c)
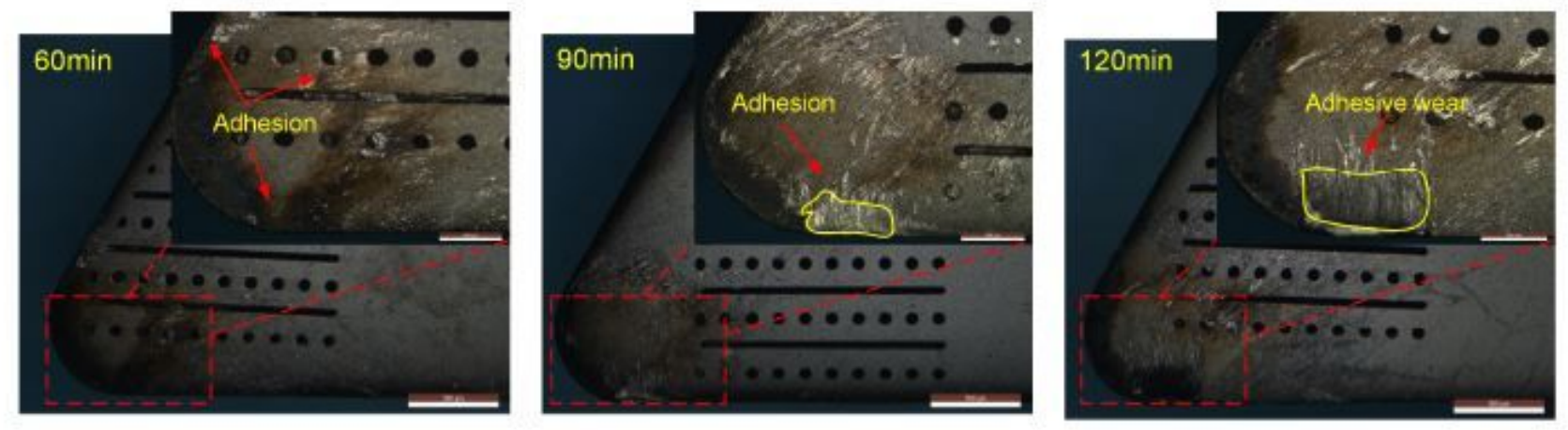

\section{Figure 11}

Images of the wear track of CCT, MP-T, MG-T and MPG-T tools at the rake face after 3 min wet cutting at the speed of $60 \mathrm{~m} / \mathrm{min}, 90 \mathrm{~m} / \mathrm{min}$ and $120 \mathrm{~m} / \mathrm{min}$, respectively $(\mathrm{a}-\mathrm{d})$ 

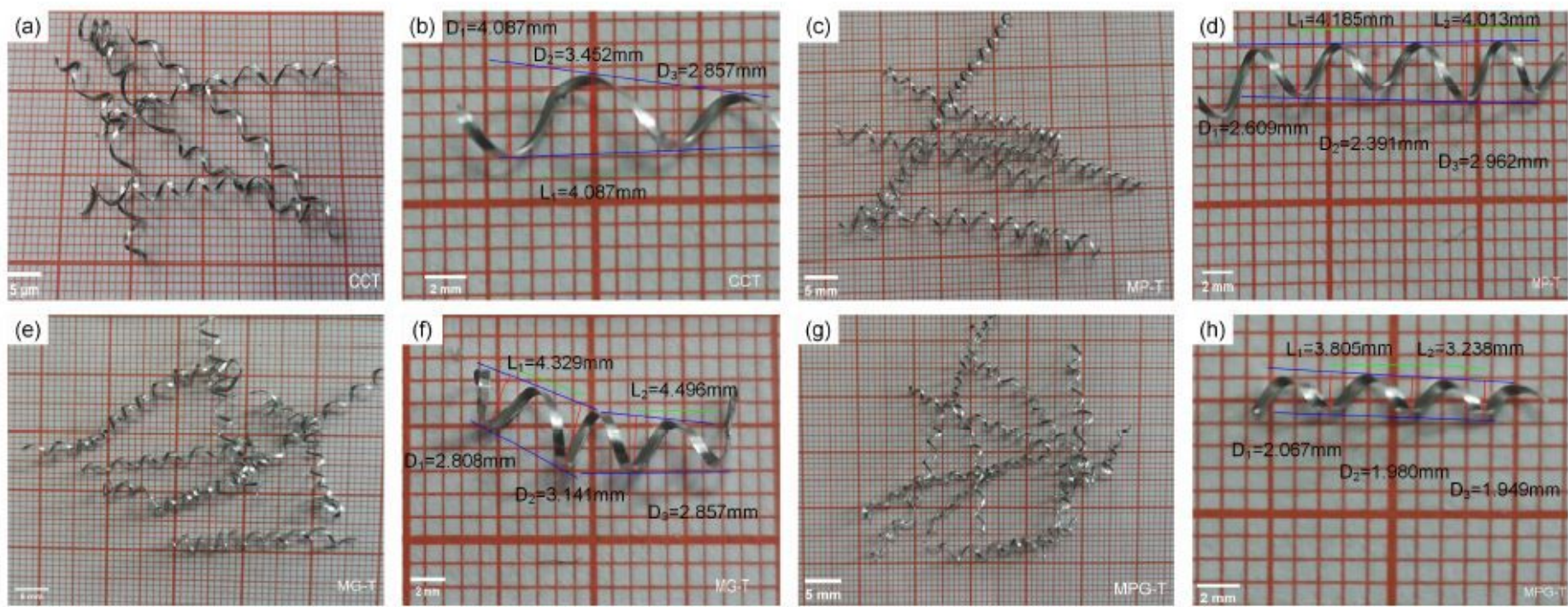

Figure 12

Chip images of four different tools at the speed of 120m/min: (a), (b) CCT; (c), (d) MP-T; (e), (f) MG-T; (g), (h) MPG-T

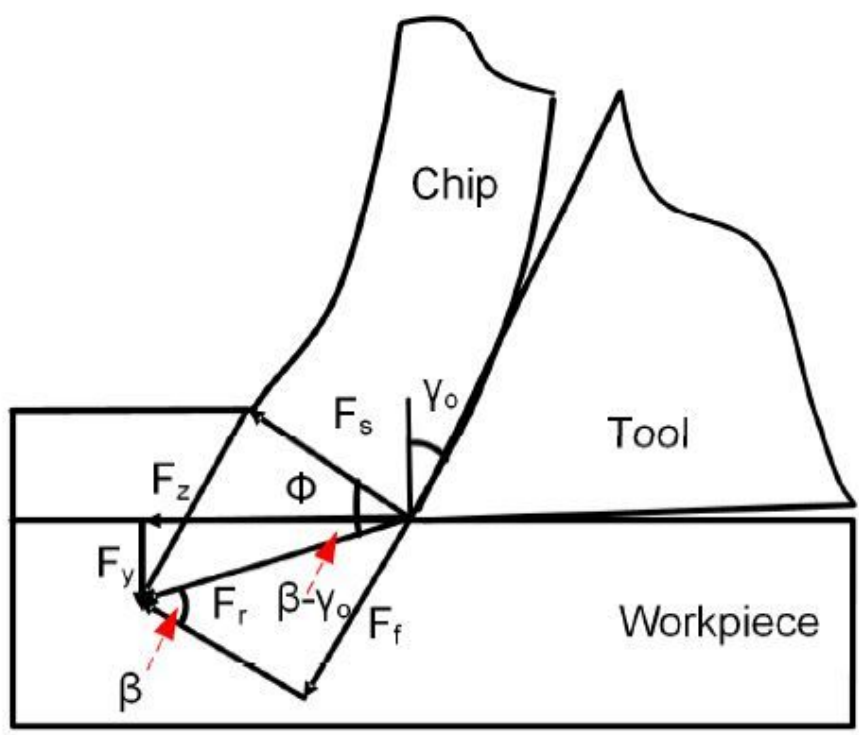

(a)

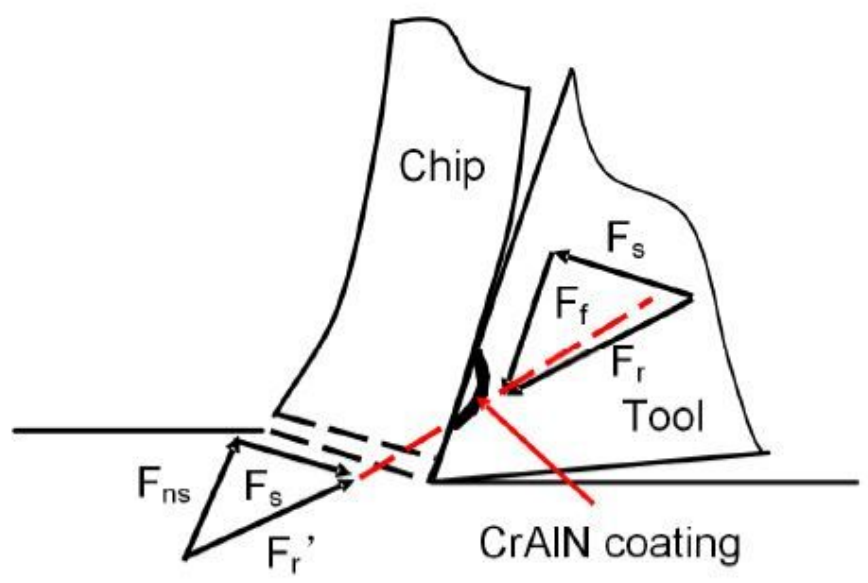

(b)

$F_{s}:$ Friction force on the shear face; $F_{n s}:$ Normal force on the shear face;

$F_{r}{ }^{\prime}$ : Resultant force of $F_{s}$ and $F_{n s} ; \quad F_{f}{ }^{\prime}:$ Friction force on the rake face;

$F_{n}$ : Normal force on the rake face; $F_{r}$ : Resultant force $F_{f}$ and $F_{n}$ 
Schematic diagram of cutting force between the rake face and the shear face during turning (a) and bending moment of tool-chip contact interface model (b) of textured tools

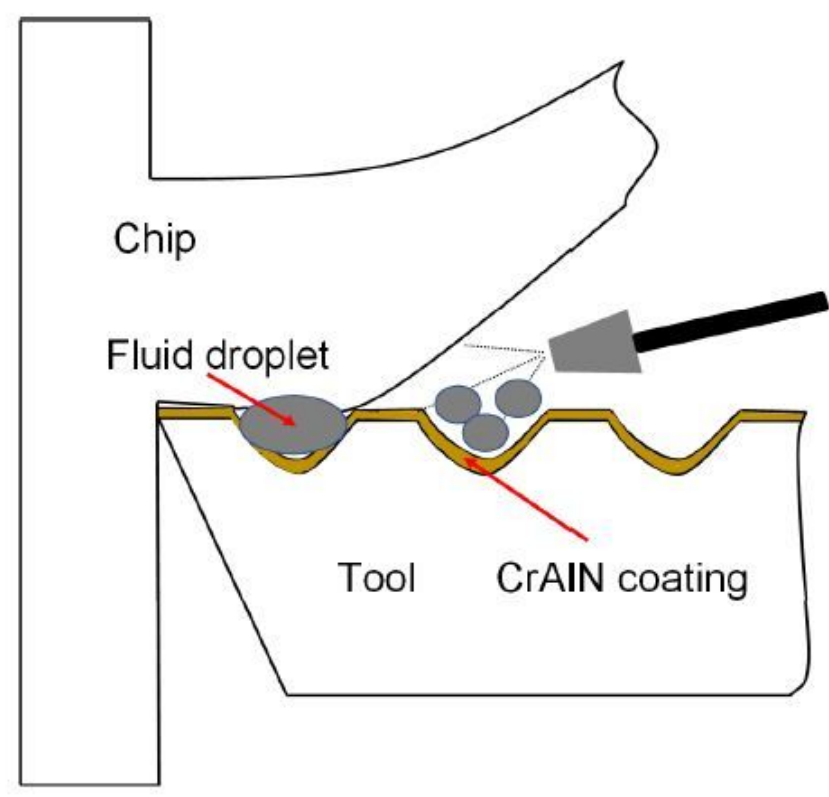

(a)

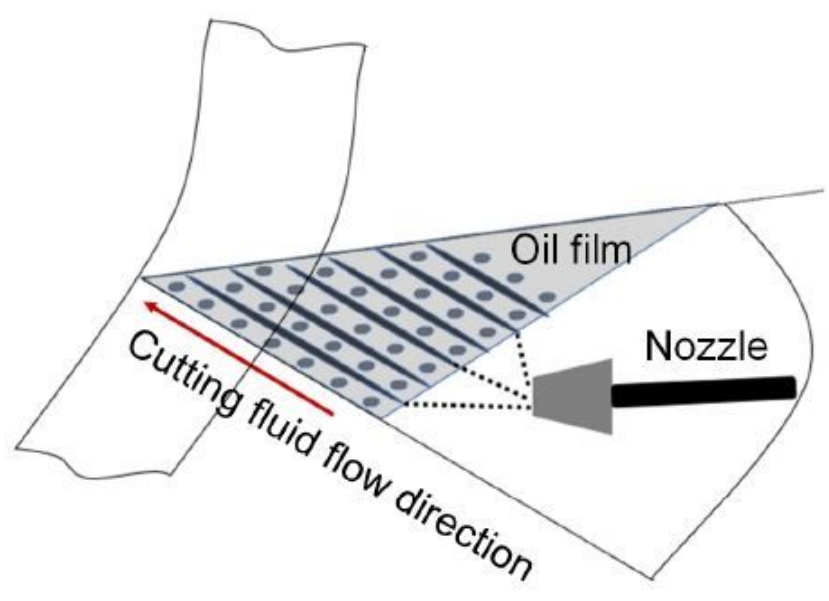

(b)

\section{Figure 14}

Schematic diagram of textured coating tool (a) and oil lubrication model (b)

\section{Supplementary Files}

This is a list of supplementary files associated with this preprint. Click to download.

- Tables.pdf 